\title{
TRIBUNAL DO JÚRI: ASPECTOS CONTROVERSOS
}

\author{
Luana Maria Moretti, Danielle Yurie Moura da Silva
}

Universidade do Oeste Paulista - UNOESTE, Curso de Direito, Presidente Prudente, SP. E-mail: luanammoretti@gmail.com

\section{RESUMO}

O presente trabalho tem como objetivo analisar o instituto do Tribunal do Júri Popular de acordo com seu funcionamento, suas bases legais, como ele é visto pela sociedade e, finalmente, apresentar uma reflexão crítica e fundamentada considerando seus pontos favoráveis e desfavoráveis, partindo do raciocínio lógico geral para o particular, por meio do método hipotético-dedutivo. Discorrendo sobre a aplicabilidade e eficiência do instituto, levando em consideração a análise de casos reais, observando a influência midiática na opinião popular e como ela é capaz de manipular a visão social. Conclui-se que a justiça e a igualdade devem estar acima de qualquer tipo de sensacionalismo midiático para que o Tribunal do Júri cumpra com a sua essência de sua existência, visto que ainda hoje a mídia possui forte influência na formação de opinião das massas populares, causando impacto no papel desempenhado pelos jurados, e, afetando negativamente o instituto do Tribunal do Júri.

Palavras-chave: Tribunal Popular do Júri - Jurados - Influência Midiática

\section{COURT OF JUSTICE: CONTROVERSIAL ASPECTS}

\begin{abstract}
The present work aims to analyze the institute of the Court of the Popular Jury according to its operation, its legal bases, as it is seen by society and, finally, to present a critical and grounded reflection considering its favorable and unfavorable points, starting from the reasoning for the particular, through the hypothetical-deductive method. Discussing the applicability and efficiency of the institute, taking into account the analysis of real cases, observing the media influence in popular opinion and how it is able to manipulate the social view. It is concluded that justice and equality must be above any type of media sensationalism in order for the jury court to comply with its essence of its existence, since even today the media has a strong influence on the formation of opinion of the popular masses, causing an impact on the role played by jurors, and negatively affecting the institute of the Jury.
\end{abstract}

Keywords: Jury's People's Court - Juries - Influence of the means of information dissemination 


\section{INTRODUÇÃO}

O Tribunal do Júri é um dos mais antigos órgãos de julgamento do mundo, antecede até mesmo o Estado democrático e organizado. Da criação do instituto até o modelo atualmente adotado houve inúmeras transformações, não só no Brasil, mas em todos os países que adotam este instituto.

A palavra "Júri" vem do latim jurare que significa "fazer juramento", faz referência ao juramento realizado pelo cidadão que compõe o tribunal do júri denominado de jurado, este é quem decide sobre o crime, de acordo com as suas convicções, consciência, entendimento do caso, valores éticos e morais, dentre outros, condenando ou absolvendo o réu, podendo chegar a um veredito diverso do que a lei determina. Assim o juramento é realizado justamente para examinar a imparcialidade e de decidir segundo sua consciência e justiça.

Logo, o juiz, nestes casos, exerce apenas a função de presidente no rito, externando o veredito dos jurados, realizando a dosimetria da pena e redigindo a sentença, ou seja, o magistrado apenas declara se o réu foi absolvido ou condenado, de acordo a vontade popular, representada pelos jurados, conforme o resultado da votação.

No Brasil, o Tribunal do Júri foi instituído em 1822, antes mesmo da criação da primeira Constituição Nacional. Com a instituição da Carta Cidadã de 1988.

$\mathrm{Na}$ época a maior dificuldade encarada pelo do Poder Judiciário foi a de submeterem-se as normas que regem o Estado Democrático de Direito, colocando em pratica o instituto do Tribunal do Júri como ferramenta de poder popular.

Desse modo, o presente tem por finalidade realizar uma reflexão sobre o Tribunal Popular do Júri, no qual o acusado é submetido ao julgamento por pessoas leigas, passando pelos pontos históricos essenciais a partir do surgimento do instituto até o seu desenvolvimento atualmente e grande contenda que enfrente o instituto em relação à necessidade ou não de fundamentação da sentença do Tribunal do Júri.

\section{METODOLOGIA}

O referente estudo realizou-se através do método hipotético-dedutivo; trata-se de um método cientifico que baseia-se em pesquisas de cunho teórico e bibliográfico.

Abordou-se uma discussão partindo do raciocínio lógico geral para o particular. Discussão feita por meio do emprego do método histórico e comparativo. Os dados coletados foram confrontados, interpretados e discutidos dialeticamente. Estas ferramentas permitiram adquirir um vasto conhecimento sobre o tribunal do júri.

\section{RESULTADOS}

Os resultados obtidos com a reflexão do presente artigo remetem a uma acalorada discussão sobre o ilustre papel do Tribunal Júri bem como sua eficácia no nosso ordenamento jurídico levando em consideração o contexto atual da sociedade.

\section{DISCUSSÃO}

Segundo a doutrina dominante o Tribunal do Júri é a forma de participação popular na justiça/judiciário. Considerado uns dos institutos mais antigos com raízes desde os primórdios, havendo inclusive relatos da sua presença nas histórias mitológicas, como na história da Orestéia, escrita pelo escritor e dramaturgo grego Ésquilo no século 458 a.C., além de relatos na antiguidade, idade média e período monárquico.

O instituto do Tribunal do Júri possui princípios exclusivos previsto no artigo 5a , XXXVIII e suas alíneas da Constituição Federal (BRASIL, 1988). São eles: a plenitude de defesa, sigilo das votações, soberania dos votos e a competência.

Art. 5o, XXXVIII - e reconhecida à instituição do júri, com a organização que lhe der a lei, assegurados: 

a) a plenitude de defesa;
b) o sigilo das votações;
c) a soberania dos veredictos;
d) a competência para o julgamento dos crimes dolosos contra a vida;

O princípio da plenitude de defesa tem como objetivo possibilitar ao réu a aplicação de todos os meios de defesa visto que, por esse princípio há a possibilidade da defesa valer-se de argumentos jurídicos e extrajurídicos na sua explanação durante a fase plenária.

O princípio do sigilo das votações visa proteger a integridade dos jurados e transmitir segurança e liberdade aos mesmos na hora da votação, uma vez que podem se sentir intimados em votar na frente do réu e sofrer posteriormente retaliação.

O princípio da soberania dos vereditos tem como objetivo principal garantir que a decisão dos jurados seja soberana, pois esta não é passível de alteração nem pelo juiz e nem pelos Tribunais Superiores (STF/STJ). Assim, em caso de recurso e pedido de revisão, a única solução é a instauração de um novo julgamento.

Este princípio decorre pelo fato que quando foi instituído o Tribunal do Júri, em 1822, as decisões eram passiveis de reforma, mesmo que apenas pelo Príncipe.

E por fim, define a competência do rito do júri que pode apenas julgar os casos de crimes dolosos contra a vida que são: homicídio, infanticídio, aborto e instigação, induzimento ou auxilio em suicídio, previstos e regulamentados pelo Código Penal.

Numa breve comparação do sistema brasileiro com o sistema norte americano as principais diferenças do rito do júri são: no EUA, é faculdade do réu, podendo o mesmo escolher entre o julgamento pelo júri ou apenas pelo juiz togado. A segunda é que não se restringe apenas aos crimes contra a vida, cabendo julgar causas penais e cíveis. E por fim, a composição dos jurados é feita tanto por juízes leigos quanto por juízes togados.

$\mathrm{Na}$ análise feita do instituto notou-se que um dos pontos negativos que torna-o alvo de severas críticas é quanto a composição dos jurados, que no Brasil é formado apenas por pessoas leigas, assim é nítido que há falta de fundamentação técnica dos votos.

O fato do conselho de sentença ser composto por pessoas sem conhecimento técnico prejudica o réu, pois estes são incapazes de analisar o caso com os mesmo olhar de um juiz de direito, sendo mais propícios a condenar um inocente, do que absolver um acusado.

Um exemplo muito usual é quando o réu utiliza seu direito constitucional de permanecerem calado, normalmente os jurados interpretam de outra forma, pendendo assim para o lado da condenação, pois não entendem a razão do princípio constitucional utilizado. Portanto, a falta de fundamentação torna as decisões passiveis de vereditos sem nexo, meramente triviais até mesmo atípicas.

Logo, a falta de fundamentação das decisões dos jurados leigos em conjunto com a falta de experiência e conhecimento técnico, o que torna o veredicto totalmente imprevisível.

Os jurados julgam baseados na emoção e não na razão, como o juiz togado agiria e também há a problemática de serem facilmente persuadidos pelos argumentos expostos no plenário, tanto pela defesa quanto pela acusação, votando conforme quem melhor pôde convencê-los é que torna o Tribunal do Júri tão contraditório.

Entretanto, o problema que mais chama a atenção está no fato de que os jurados não podem sofrer nenhum tipo de influência externa na hora de decidir seu voto. Contudo, atualmente, com o avanço da imprensa observa-se que os casos polêmicos de crime contra a vida despertam o interesse da mídia e da população.

Desta forma são alvos de várias manchetes sensacionalistas, trazendo inclusive com informações falsas, sem nexo, além de conter inúmeros prejulgamentos antes mesmo da finalização do inquérito, condenando o acusado antes mesmo de haver um devido processo legal do qual ele tem direito. 
Vale ressaltar que a opinião do júri não pode ser influenciada de forma alguma por fatores externos ao julgamento como forma de garantia do princípio do devido processo legal e da ampla defesa, além do princípio da presunção da inocência.

Em vista disso, é necessário atentar-se a responsabilidade inerente às decisões tomadas no júri, para ambos os lados, defesa e acusação, disputam através dos seus discursos a decisão do júri. Cabendo ao mesmo balancear o conteúdo apresentado, analisando todos os pontos expostos durante a sessão plenária, pois se encontra em jogo os dois maiores bens jurídicos inerentes ao ser humano, à vida suprimida e a liberdade do acusado.

Portanto, o Tribunal assume a responsabilidade de julgar os casos focados na ética e legalidade de acordo com cada situação e, por conseguinte, não podem ser influenciados pela mídia.

Apesar disso, os casos que mais chamam a atenção da sociedade são divulgados pela mídia e posteriormente julgados pelo conselho de sentença, levando os mesmos a cometerem erros durante o julgamento, o que afeta negativamente a imagem do júri.

Logo os jurados, que são pessoas leigas sem conhecimento nenhum da lei ou interesse em questionar os fatos expostos pela mídia, acabam seguindo o mesmo pensamento, o que sem dúvida nenhum influencia a convicção do jurado e prejudica tanto o réu, como a imagem do judiciário e consequentemente o instituto.

Neste ponto, demonstra-se substancialmente importante a atenção em relação ao que a mídia divulga, visto que muitos dos casos julgados no Tribunal do Júri são excessivamente divulgados pela mídia, geralmente com base em informações falsas, clamando por uma justiça diferente da forma aplicada pela lei, o que atrai a atenção das pessoas, sensibilizando-as.

Consequentemente acaba causando decisões absurdas no tribunal, inclusive prejudicando o futuro do réu ou a finalidade de processo.

\section{CONCLUSÃO}

Através do estudo é possível concluir que o Tribunal Popular do Júri desempenha uma função importante na sociedade por ser uma forma de participação popular no Poder Judiciário.

O julgamento dos crimes dolosos contra à vida realizado pelo Júri Popular tem suas decisões praticamente baseadas em valores éticos e morais intrínsecos à cultura da comunidade.

Portanto, constatou-se que o instituto possui aspectos favoráveis e desfavoráveis. Dentre os aspectos favoráveis estão à efetivação da garantia de liberdade individual aproximando a comunidade do judiciário, porém, o principal o mais importante é que o Tribunal do Júri é visto como símbolo de cidadania e em alguns casos até como justiça.

Entretanto, a maior crítica citada e estudada está na influência que a mídia pode causar sobre os seus espectadores com a divulgação de matérias inverídicas e sensacionalistas sobre o crime. Logo, o jurado leigo, que geralmente tem contato com essas notícias, tem o seu veredicto viciado por elas, levando-os cometerem diversos erros como absolvendo culpados e na maioria das vezes, condenando inocentes ocasionando um terrível dano à sociedade como um todo.

Dessa forma, diante de todo o exposto acima, podemos concluir que a justiça e a igualdade devem estar acima de qualquer tipo de sensacionalismo midiático para que o Tribunal do Júri cumpra com essência de sua existência.

Para isso é necessário conscientizar os jurados, demonstrando previamente a importância do papel por eles desempenhado e as consequências dos atos por eles praticados, além de orientá-los sobre o mecanismo disposto na legislação. 


\section{REFERÊNCIAS}

BITENCOURT, C. R. Tratado de direito penal 2: parte especial dos crimes contra a pessoa. 12a ed. São Paulo; Saraiva, 2012.

BOMFIM, E. M. Curso de processo penal. 11 ed. São Paulo: Saraiva, 2016.

CAMPOS, W. C. Tribunal do júri: teoria e prática, 4. ed., São Paulo, Atlas, 2015.

CAPEZ, F. Curso de processo penal. 21 ed. São Paulo. Saraiva. 2014.

COSTA, F. V. O mito, a linguagem e o discurso no Tribunal do Júri. Revista do Conselho Federal da Ordem dos Advogados do Brasil - OAB. Belo Horizonte. V. 2, n. 3, jul. e dez, 2012. Disponível em: <http://www.mp.go.gov.br/revista/edicoes_anteriores/pdfs_1/0\%20mito,\%20a\%20linguagem\%2 0e\%20o\%20discurso\%20no\%20tribunal\%20do\%20juri.pdf>. Acesso em: 17 out. 2017.

DOTTO, R. F. O Júri no Mundo - Direito Comparado. Revista Jus Navigandi., nov. de 2014. Disponível em: <https://jus.com.br/artigos/33862/o-juri-no-mundo-direito-comparado>. Acesso em: 18 de abr. de 2018.

GOMES, L. F.; SICA, A. P. Z. O tribunal do júri no direito comparado. Teresina, v. 01, n. 886, dez. 2005. Disponível em: <https://jus.com.br/artigos/7655/o-tribunal-do-juri-no-direito-comparado>. Acesso em: 18 nov. 2017.

GOULART, F. R. Tribunal do júri: aspectos críticos relacionados à prova, 1a ed., São Paulo, Atlas, 2008.

LOPES, A J, Direito processual penal, 14. ed., São Paulo, Saraiva, 2017.

NUCCI, G. S. Tribunal do júri, 6 ed., Rio de Janeiro, Forense, 2015.

RANGEL, P. Tribunal do júri: visão linguística, histórica, social e jurídica. 4a ed.; São Paulo. Atlas. 2012.

REIS, W. J.. O júri no Brasil e nos Estados Unidos. Algumas considerações. Revista Jus Navigandi, Teresina, ano 18, n. 3490, 20 jan. 2013. Disponível em: <https://jus.com.br/artigos/23474/o-jurino-brasil-e-nos-estados-unidos>. Acesso em: 20 abr. 2018.

VIEIRA, A. L. M. Processo penal e mídia. 1 ed. São Paulo. Revista dos Tribunais. 2003. 